\title{
Functional Analysis Of The Mutations Of E Cadherin Exon 4-5, Exon 7, Exon 8, Exon 9 And Exon 16 In Sporadic Infiltrating Ductal Carcinoma Of The Breast
}

\author{
Malathi Veeramani ${ }^{1}$, Revathi Kasthuri ${ }^{2}$ \\ ${ }^{l}$ Department of Biochemistry, Ethiraj college for women, Chennai, Tamilnadu, 600008 ,India . \\ ${ }^{2}$ Department of Zoology, Ethiraj college for women, Chennai, Tamilnadu, 600008 ,India. \\ e mail ; malathiveeramani@gmail.com
}

\begin{abstract}
E-cadherin mutations are a major step in the metastatic progression. Mutated cadherins contributes to different aspects of cancer progression like drug resistance, angiogenesis, cancer cell invasion and metastasis. Thus cadherins can be regarded as a valuable diagnostic and prognostic indicators as well as potential therapeutic targets of cancer therapy in future. Identification of E-cadherin mutations and characterization of the mutated protein may improve our understanding of how cells escape from their normal location and spread through the body. The present study aimed at analyzing the functional consequences of such E- cadherin mutations in 50 patients with infiltrating ductal carcinoma of the breast.
\end{abstract}

Key words: Breast Cancer, E-cadherin, Ductal carcinoma, Mutations

\section{Introduction}

Breast cancer is a common form of cancer in woman. Every woman is at the risk of developing breast cancer. One in 20 women is affected by this disease at sometimes in their lives. Even men can develop breast cancer. Early detection of the disease increase chances of cure. Worldwide, breast cancer is the most common invasive cancer in women and the second leading cause of cancer death ${ }^{1,2}$.

In order to understand the mechanisms of metastasis, one must first understand about the cell adhesion molecules in tumors as well as in normal tissues. The perturbation of cadherin function causes temporal or permanent disaggregation of tumor cells and may thus promote the invasion and metastasis of such cells.

The human epithelial (E)-cadherin gene CDH1 maps to chromosome 16q22.1. It encompasses 16 exons and spans a region of approximately $100 \mathrm{~kb}$. The exons range from 115 to $2245 \mathrm{bp}$. There are 15 introns ranging from $120 \mathrm{bp}$ to $65 \mathrm{~kb}$. The intron-exon boundaries are highly conserved in comparison with other classical cadherins .

E-cadherin is a calcium dependant cell- cell adhesion molecule. It plays an essential role in the formation and maintenance of normal architecture and functioning of epithelial tissues. This $120 \mathrm{KD}$ transmembrane glycol protein is localized in the lateral cell- cell contacts and in the Zonula adherens junction. It mediates intercellular adhesion through homophilic interaction ${ }^{20}$.

The adhesive function of E-cadherin is dependent on the interaction of its cytoplasmic domain with catenins, namely $\beta$ catenin and $\gamma$ catenin . They link cadherins via $\alpha$ catenin to the actin cyto skeleton. Phosphorylation of $\beta$ catenin and another catenin called $\mathrm{p} 120^{\mathrm{ctn}}$ regulate cell- cell adhesion through the Ecadherin ${ }^{13}$. Cell- cell adhesion determines cell polarity and participates in cell differentiation, establishment and maintenance of tissue homeostasis. During oncogenesis this organized adhesion is disturbed by genetic and epigenetic changes. This results in changes in signaling, loss of contact inhibition and altered cell migration and stromal interaction ${ }^{22}$.

As far as normal adult epithelial tissue structure and integrity is concerned, E-cadherin is also involved in its maintenance and homeostasis. Cadherin mediated adhesion is a dynamic process that is regulated by several signal transduction pathways. There is also evidence that cadherins are not only targets for signaling pathways that regulate adhesion, but also send signals by themselves. These signals regulate basic cellular processes, such as migration, proliferation, apoptosis and cell differentiation ${ }^{14}$.

\section{Patients and tissue samples}

\section{Materials and Methods}

50 Breast cancer patients were involved in this study. The patients were aged between 30-60 years. Informed consent was obtained from all participants. The samples were collected from Madras Medical college ,Chennai, Tamil Nadu ,India ,after obtaining the ethical clearance for the same (No: 13112010). The tissue samples were collected from the patients soon after their mastectomy and stored in phosphate buffered saline in 
a deep freezer. Portion of the tissue was sliced and studied for pathological changes. The samples confirmed malignant were selected for the study. Normal tissue isolated from the same patient served as controls.

\section{Genomic DNA isolation}

DNA was extracted from all tissue samples using the HipureA ${ }^{\mathrm{TM}}$ mammalian genomic DNA isolation /purification spin Kit, Himedia. The isolated DNA was labeled appropriately and stored at $-20^{\circ} \mathrm{C}$.

\section{PCR amplification of the E-Cadherin gene}

The PCR amplification was carried out as per the protocol of Berx et al., 1995. PCR was performed for 35 cycles consisting of $94{ }^{\circ} \mathrm{C}$ for $30 \mathrm{~s}, 55-70{ }^{\circ} \mathrm{C}$ for $30 \mathrm{~s}$ and $72^{\circ} \mathrm{C}$ for $45 \mathrm{~s}$ on a thermal cycler. The PCR reaction mixture consisted of $7 \mu \mathrm{l}$ of genomic DNA, $2+2 \mu \mathrm{l}$ of primers of concentration 20 picomoles , $25 \mu \mathrm{l}$ of PCR master mix and $14 \mu \mathrm{l}$ of distilled water. The amplified PCR products were then subjected to agarose gel electrophoresis. The bands were identified and photographed.

\section{Sequencing of the PCR products}

The amplified PCR products were then purified, isolated and sequenced. The cycle sequencing reaction was performed using BigDye terminator V3.1 cycle sequencing Kit containing AmpliTac DNA polymerase (from Applied Biosystems, P/N: 4337457). The sequencing reaction - mix was prepared by adding $1 \mathrm{ul}$ of BigDye v3.1, 2ul of $5 \mathrm{x}$ sequencing buffer and $1 \mathrm{ul}$ of $50 \%$ DMSO. To $4 \mathrm{ul}$ of Sequencing reaction - mix was added 4 Pico moles of primer (2ul) and sufficient amount of plasmid. The constituted reaction was denatured at $95^{\circ} \mathrm{C}$ for 5 minutes. Cycling began with denaturing at $95^{\circ} \mathrm{C}$ for 30 seconds, annealing at $52^{\circ} \mathrm{C}$ for 30 seconds and extension for 4 minutes at $60^{\circ} \mathrm{C}$ and cycle repeated for a total 30 cycles in a MWG thermocycler. The reaction was then purified on sepheadex plate (Edge Biosystems) by centrifugation to remove unbound labelled and unlabelled nucelotides and salts. The purified reaction was loaded on to the 96 capillary ABI 3700 DNA analyzer and electrophoresis was carried out for 4 hours.

\section{Mutational screening}

The sequence of normal and tumour DNA was compared using NCBI nucleotide blast search. blast.ncbi.nlm.nih.gov/

\section{Functional analysis of the mutations}

The identified mutations were then studied for their functional implications. The nucleotide sequences of the normal and tumor samples were translated using the Expasy translate tool. The translated aminoacid sequences were then compared using the NCBI protein blast tool.

\section{Results and discussion}

Comparison of the amplified aberrant tumour DNAs with the amplified normal DNA isolated from the normal breast tissue, revealed various mutations. The sequences were submitted to Gen Bank and an accession number was provided for the same (accession number JX 519564). The nucleotide sequences were then translated to the amino acid sequences in three reading frames in the $5^{\prime} \rightarrow 3^{\prime}$ direction.(Table 1).

\section{Exon 4-5 mutations}

Upon translation of the nucleotide sequences into the protein sequences using the Expasy translation tool the following changes were observed in the 3 reading frames in the $5^{\prime} \rightarrow 3^{\prime}$ direction. Exon 4-5 mutations resulted in 4 aminoacid changes. (Data 1-3)

According to reading frame 1 : aromatic amino acid Trptophan (W) was replaced by an aliphatic aminoacid Glycine (G), positively charged aminoacid Arginine (R) was replaced by negatively charged Glutamate (E), uncharged Glutamine (Q) was replaced by positively charged Arginine (R). The replacement of aliphatic aminoacids Ile by val may not have much functional significance.

According to reading frame 2: aromatic amino acid Phenylalanine(F) was replaced by aliphatic amino acid Leucine (L); Glycine (G) was replaced by Alanine (A); positively charged Arginine (R) was replaced by negatively charged Glutamate (E) ; negatively charged Glutamate (E) was replaced by positively charged Lysine (K).

According to reading frame 3 : nonpolar aliphatic Leucine (L) was replaced by aromatic amino acid Tryptophan (W) ; Alanine, nonpolar amino acid (A) was replaced by polar Glutamine (Q); negatively charged Glutamate (E) was replaced by positively charged Arginine (R). Replacement of polar amino acids Asparagine (N) by Serine (S) was also observed which may not have much functional consequences.

These amino acid changes observed may greatly influence the structure of the E-cadherin protein and consequently may result in functional variation. The exon 4-13 is involved in a molecular zipper mediating cellcell adhesion ${ }^{19}$ and hence the detected mutations in this exonic region may have significant role in determining the metastatic potential of the tumor . 


\section{Exon 7 mutations}

Exon 7 mutations resulted in an array of amino acid changes brought about by the reading frame shift caused by the deletion of nucleotides. (Data 4)

According to reading frame 1 : the amino acid changes observed were Glutamine (Q) to Serine (S); Valine (V) to Glycine $(\mathrm{G})$; Lysine (K) to Serine (S); Glutamate (E) to Argine (R); Aspartate (D) to Glycine (G); Proline (P), Non polar amino acid to Cysteine (C), polar amino acid; Glutamate (E) to Glycine (G); Non polar Valine (V) to polar Glutamine (Q); negatively charged Glutamate (E) to uncharged Methionine (M); Aspartate (D) to Glutamate $(\mathrm{E})$; Lysine $(\mathrm{K})$ to Threonine $(\mathrm{T})$ and Valine $(\mathrm{V})$ to Isoleucine $(\mathrm{I})$.

According to reading frame 2: no significant similarity was observed between the normal and the cancerous protein sequences.

According to reading frame 3: the changes observed were; Replacement of Valine (V) by Leucine (L) ; Valine (V) by Isoleucine (I); Serine (S) by Glutamine (Q); Tyrosine (Y) by Trptophan (W) and Aspartate (D) by Glutamate (E) .

As reported by earlier studies these changes of amino acids may alter the $\mathrm{Ca}^{2+}$ binding sites of the protein.

Earlier studies with lobular breast tumors reported that $2(10 \%)$ of the 20 cases examined, a sequence abnormality was detected in E-cadherin exon 7, i.e. a point mutation of codon 315 (AAT to AGT) which resulted in a single amino acid substitution (Asparagine to Serine). They reported that this mutation may abolish the E-cadherin-mediated cell-cell adhesion and be at least partly responsible for the weak intercellular adhesiveness and scattered histological pattern of the tumor ${ }^{10}$.

In vitro created missense mutations in the $\mathrm{Ca}^{2+}$ binding sites, encoded by exon 7 of the mouse Ecadherin gene ,abolishes the adhesiveness of the protein ${ }^{15}$.

In gastric cancers sequencing of the E-cadherin gene revealed a $\mathrm{G}$ to $\mathrm{T}$ nucleotide substitution in the donor splice consensus sequence of exon 7 , leading to a truncated gene product ${ }^{8}$.

\section{Exon 8 and Exon 9 mutations}

Earlier studies of E-cadherin transcripts in 63 gastric carcinomas by RT-PCR and direct cDNA sequencing revealed six exon8 skippings, seven exon 9 skippings and four in frame deletions .Exon 8 and exon 9 could be considered as a mutation hot spot in E-cadherin gene. Exon skipping of exon 8 or 9 destroys essential calcium binding sites of the E-cadherin gene ${ }^{3}$.

\section{Exon 8 mutations}

According to reading frame 1 and 2 : no significant similarity was observed between the normal and cancerous protein. However with reading frame 3 the following changes were observed. Arginine (R) to Tryptophan $(\mathrm{W})$; Proline $(\mathrm{F})$ to Glycine $(\mathrm{G})$ and uncharged Asparagine $(\mathrm{N})$ to positively charged Histidine $(\mathrm{H})$. (Data 5)

\subsubsection{Exon 9 mutations,}

According to reading frame 1: exon 9 mutations resulted in the replacement of Lysine $(\mathrm{K})$ to Aspargine (N). However no change was observed between the cancerous and the normal protein sequences with respect to reading frame 2 and 3.(Data 6,7)

E-cadherin harboring an in-frame deletion of exon 8 had reduced ability to activate Rac1 and to inhibit Rho.The lack of Rac1 activation influenced the downstream signaling of Rac1, as shown by a decrease in the binding of the Rac1 effector protein to rac1-GTP.Reduced membranous localization of p120 -catenin in mutant E-cadherin expressing cells was associated with the lack of negative regulation of Rho by mutant E-cadherin. The enhanced motility and invasion associated with mutant E-cadherin was sensitive to the inhibition of Rac1 and Rho. Therefore it was concluded that the mutation of E-cadherin had a reciprocal influence on Rac1 and Rho activation and that Rac1 and Rho are involved in the establishment of the migratory and invasive phenotype of tumor cells harboring an E-cadherin mutation ${ }^{6}$.

11 missense mutations, scattered from exon 3 to 16 have been identified by various researchers. The effects of most of these mutations must be examined at protein functional level.

\section{Exon 16 mutations}

Exon 16 encodes the cytoplasmic tail of the E-cadherin protein and is involved in transducing signals inside the cell. Exon 16 mutations resulted in the replacement of a stop codon by Leucine (L) according to reading frame 2.(Data 8 ) 
With respect to reading frame 1 and 3 no significant similarity was observed between the cancerous and the normal E-cadherin protein sequences.

The C-terminal cytoplasmic domain of $\sim 150$ residues is highly conserved in sequence, and has been shown experimentally to regulate the cell-cell binding function of the extracellular domain of E-cadherin, possibly through interaction with the cytoskeleton. The juxtamembrane region of the cadherin cytoplasmic tail has been identified as a functionally active region supporting cadherin clustering and adhesive strength.

Exon 14-16 encode for the cytoplasmic domain of the protein. Exon 16 is the terminal end of the gene encoding the cytoplasmic tail necessary for binding $\beta$ catenin or plakoglobin. The cytoplasmic tail of E-cadherin is linked via catenins to the actin cyto skeleton ${ }^{4}$.

The cytoplasmic domain of E-cadherin may modulate the Wnt signalling pathway by inhibiting the availability of free cytoplasmic $\beta$-catenin. In response to wnt signaling, cytoplasmic beta-catenin is stabilized, accumulates in the cytoplasm and enters the nucleus, where it finds a partner,a member of the DNA binding protein family LEF/TCF (Tcell factor-lymphoid enhancer factor). Together they activate new gene expression programs. One of the target genes for $\beta$-catenin/TCF encodes c-MYC protein ${ }^{8}$. This clearly explains the constitutive activation of the wnt pathway which can lead to cancer.

In general studies have reported that all these mutations are predicted to generate a secreted E-cadherin fragment instead of a transmembrane protein with cell-cell adhesion activity. Soluble E- cadherin fragments have been identified in the serum and urine of cancer patients ${ }^{12}$ and in the medium of the human breast cancer cells MC7 ${ }^{5,23}$.

It is expected that these mutations will have severe effects on the normal functions of the E-cadherin protein. Aberrant expression of E-cadherin has been associated with the development of metastases in patients with breast cancer. Even though the expression of E-cadherin has been studied in primary breast tumors, little is known about its expression at the distant metastatic sites ${ }^{16}$.

In breast cancer, inactivating point mutations in the E-cadherin gene are frequently found in invasive lobular carcinoma (ILC) but never in invasive ductal carcinoma (IDC). The method of blocking E-cadherin down regulation in tumors is one of the important future approaches in gene therapy. To target this molecule is the logical path to prevent metastazing potential of almost any epithelial tumor. E-cadherin down regulation is caused by many different mechanisms, ranging from mutations and gross deletions to repression of gene transcription, as well as signal transduction stimulation of E-cadherin adhesion complex formation.

Loss of E-cadherin expression or E-cadherin mutations appears to be a major determinative step in the metastatic progression. Therefore identification of E-cadherin mutations and deletions in human cancers may improve prognosis in these cancers, and further helps us to understand how cells escape from their normal location and spread through the body.

\section{Acknowledgements}

The authors thank the support and guidance offered by Asia's first women Neuro surgeon Dr.T.S.Kanaka.

\section{Conflict of Interest}

None

\section{References}

[1]. Berx G, Clenton-jansen AM, Nollet F, De Leeuw WJF, Van de Vijver MJK, Cornelisse C and Van Roy F : E- cadherin is a tumor/invasion suppressor gene mutated in human lobular breast cancers. EMBO J 14:6107-6115, 1995

[2]. Berx G, States K, Van Hengel J, Molemans F, Bussemakers MJG, Van Bokhoven A and Van Roy F: Cloning and characterization of the human invasion suppressor gene E cadherin (CDH1). Genomics $26: 281-289,1995$

[3]. Berx G, Becker KF, Hofler H and Van Roy, F: Mutations of the human E cadherin (CDH1) gene. Hum. Mutat. 12:226-237, 1998.

[4]. Cowin, P: Unraveling the cytoplasmic interactions of the cadherin super family. Proc.Natl Acad.Sci.USA., 91 : 10759-10761. 1994

[5]. Damsky CH, Richa J, Solter D, Knudsen K and Buck CA: Identification and purification of a cell surface glycoprotein mediating intercellular adhesion in embryonic and adult tissue. Cell $34: 455-466.1983$

[6]. Deplazes J, Fuchs M, Rauser S, Genth H, Lengyel E, Busch R and Luber B: Rac1 and Rho contribute to the migratory and invasive phenotype associated with somatic E cadherin mutation. Hum.Molec.Genet. $18: 3632-3644,2009$

[7]. Fleming T, Hay M, Javed Q : Epithelial differentiation and intercellular junction formation in the mouse early embryo. Development Suppl, $17: 105$ - 113. 1992

[8]. Guilford P, Hopkins J, Harraway J, McLeod M, MnLeod N, Harawira, P, Tait R, Miller, A and Reeve, AE: E cadherin germline mutations in familial gastric cancer. Nature ., 392: 402-405, 1998

[9]. Hyafil F, Morello D, Babinet , C and Jacob, F: A Cell surface glycoprotein involved in the compaction of embryonal carcinoma cells and cleavage stage embryos. Cell $21: 927$ - 934. 1980.

[10]. Kanai Y, Oda T, Tsuda H, Ochiai A and Hirohashi S: Point mutation of the E-cadherin gene in invasive lobular carcinoma of the breast.Jap.J.Cancer Res.,85:1035-1039. 1994

[11]. Kashiwaba M, Tamura G, Suzuki Y, Maesawa C, Ogasawara S, Sakat AK and Satodate R : Epithelial-cadherin gene is not mutated in ductal carcinomas of the breast. JpnJ cance Res 86:1054-1059,1995

[12]. Katayamma
Yasumoto M, Kato I:. Soluble E-cadherin fragments increased in circulation of cancer patients; Br J Cancer., 69: $580-585,1994$ 
[13]. Mareel M, Berx G, Van Roy F and Bracke M: The cadherin/catenin complex: A target for anti invasive theraphy? J cell Biochem. 61: 524-530. 1996

[14]. Morin PJ, Sparks AB, Korinek V, Barker N, Clevers H, Vogelstein B and Kinzler KW: Activation of $\beta$ - catenin - Tcf signaling in colon cancer by mutations in $\beta$-catenin or APC.Science ., $275: 1787-1789,2007$

[15]. Ozawa M, Engel $\mathrm{J}$ and Kemler R: Single aminoacid substitutions in one $\mathrm{Ca}^{2+}$ binding site of uvomorulin abolish the adhesive function. Cell., $63: 1033-1067,1990$.

[16]. Paul J, Mark A and Celina G:. E-cadherin expression in primary carcinomas of the breast and its distant metastases, Breast Cancer Res., 5(6) : R217-R222, 2003

[17]. Rietmacher D, Brinkmann V and Birchmeier CA: Targeted mutation in the mouse E-cadherin gene results in defective preimplantation development. Proc Nat Acad Sci USA., 92 : 955 - 859,1995

[18]. Sefton M, Johnson M, and Clayton L: Synthesis and phosphorylation of uvomorulin during mouse early development. Development (Cambridge, UK), $115: 313-318,1992$.

[19]. Shapiro L, Fannon AM, Kwong PD, Thompson A, Lehmann MS, Grubel G, Legrand JF, Alsenielsen J, Colman DR and Hendrickson WA:. Structural basis of cell-cell adhesion by cadherins. Nature., 374 : 327-337. 1995

[20]. Takeichi M : Morphogenetic roles of classic cadherins. Curr Opin Cell Biol., 7 : 619-627. 1995.

[21]. Thiery JP: Epithelial - mesenchymal transitions in tumour progression, Nat Rev Cancer., $2: 442-454,2002$.

[22]. Van Roy, F and Berx, The cell adhesion E-cadherin.Cell Mol Life Sci., 65 : 3756-3788,2008.

[23]. Wheelock MJ, Buch CA, Bechtol KB and Damsky CH: Soluble 80KD fragment of cell-CAM120/80disruptscell-celladhesion: J cell Biochem., $34 ; 187-202.1987$.

\section{Data 1: Protein Blast result of Exon 4-5 Tumor Vs normal, Reading Frame 1}

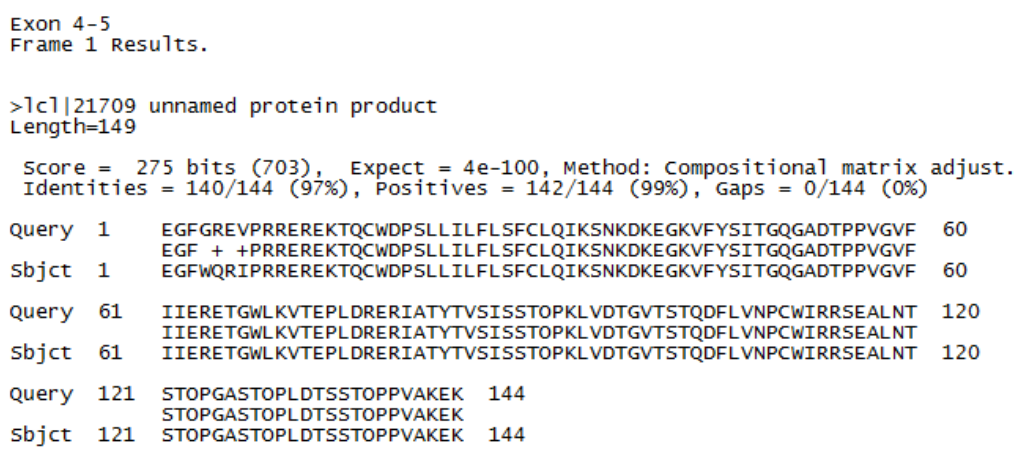

Data 2: Protein Blast result of Exon 4-5 Tumor Vs normal, Reading Frame 2
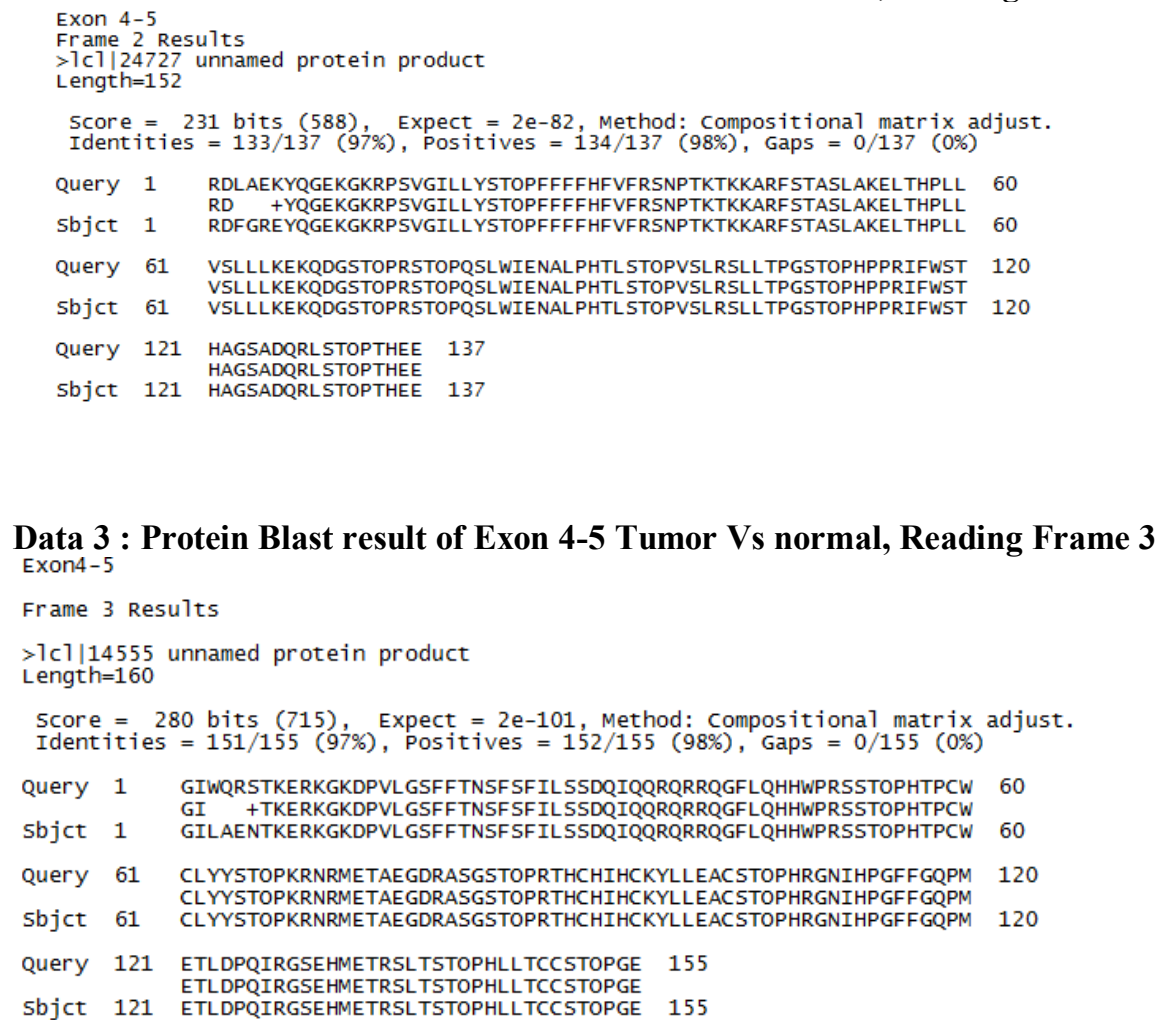


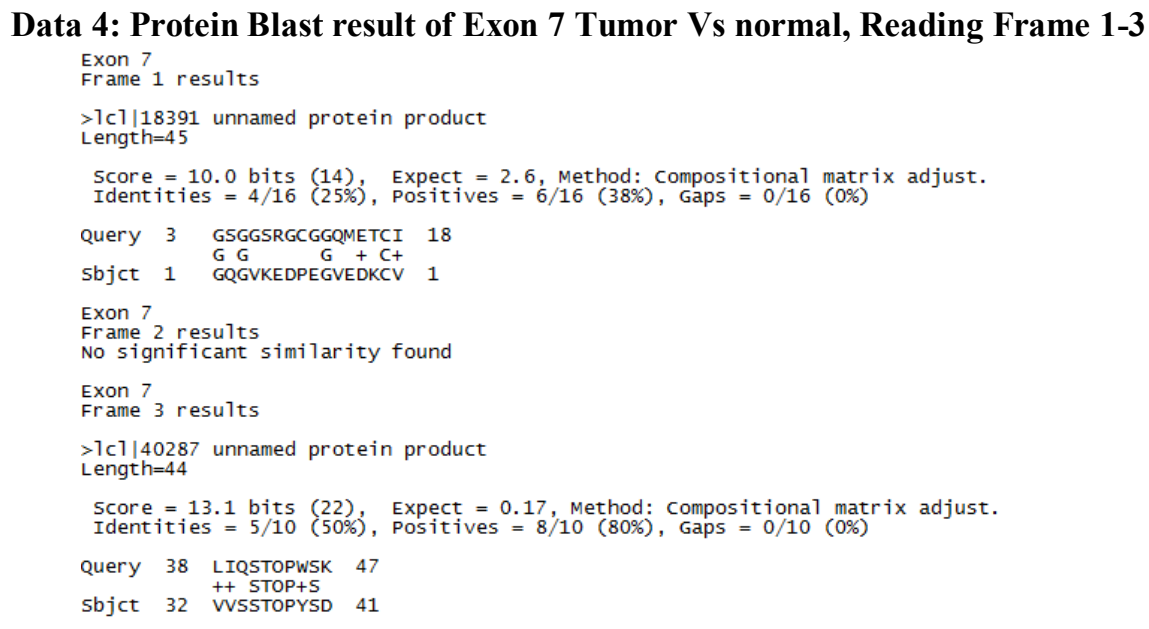

Data 5: Protein Blast result of Exon 8 Tumor Vs normal, Reading Frame 1-3

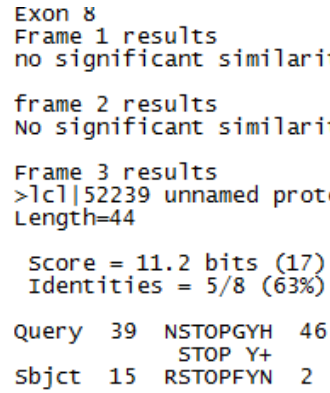

Data 6: Protein Blast result of Exon 9 Tumor Vs normal, Reading Frame 1,2

Exon 9

Frame 1 results

$>1 c 117939$ unnamed protein product

Length $=6$

Score $=126$ bits (316), Expect $=3 e-44$, Method: Compositional matrix adjust.

Query 1 STOPCSTOPCPQYPSVGGCIHHIESTOPSTOPWWTICRHHKSSEQRWHFENSKGLYGTWQ 60 $\begin{array}{llll}\text { sbjct } & 1 & \text { STOPCSTOPCPQYPSVGGCIHHIESTOPSTTOPWWTICRHHKSSEQRWHFENSKGLYGTWQ } \\ \text { STOPCSTOPCPQYPSVGGCIHHIESTOPSTOPWWTICRHHKSSEQRWHFENSKGLYGTWQ } & 60\end{array}$

Query 61 DAETGN 66

sbjct 61 DAETGK 66

Frame 2 Results

$>1 \mathrm{c} 1 \mid 61561$ unnamed protein product Length $=58$

Score $=118$ bits (295), Expect $=2 \mathrm{e}-41$, Method: Compositional matrix adjust. Identities $=57 / 57(100 \%)$, Positives $=57 / 57(100 \%)$, Gaps $=0 / 57(0 \%)$

Query 1 DADAPNTPAWEAVYTILNDDGGQFVVTTNPVNNDGILKTAKVCMETVPGKMETQKLA 57 $\begin{array}{llll}\text { sbjct } & 1 & \text { DADAPNTPAWEAVYTILNDDGGQFVVTTNPVNNDGILKTAKVCMETVPGKMETQKLA } \\ & \text { DADAPNTPAWEAVYTILNDDGGQFVVTTNPVNNDGILKTAKVCMETVPGKMETQKLA } & 57\end{array}$ 
Data 7: Protein Blast result of Exon 9 Tumor Vs normal, Reading Frame 3

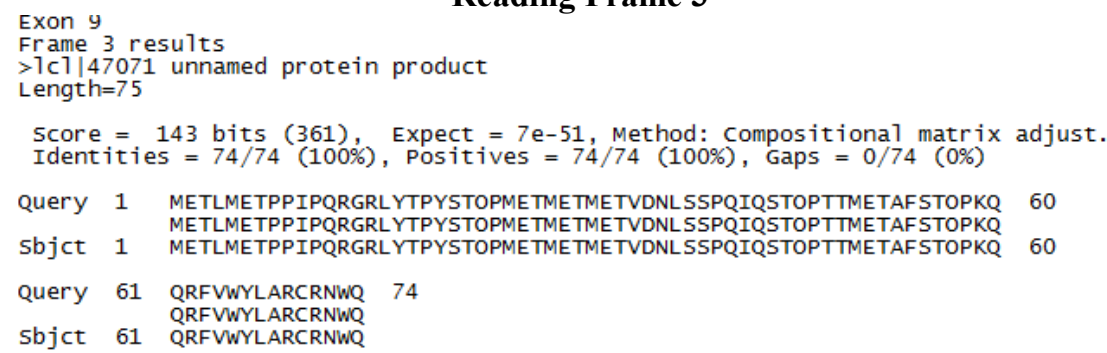

Data 8 : Protein Blast result of Exon 16 Tumor Vs normal, Reading Frame 1-3

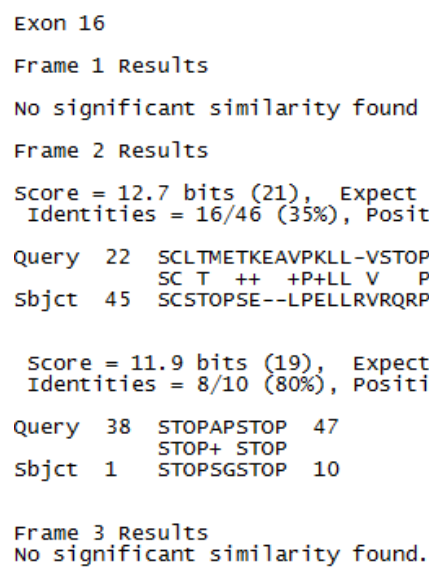

Table 1 : Functional analysis of the $\mathbf{E}$ cadherin mutations observed- Protein polymorphisms

\begin{tabular}{|l|l|l|l|}
\hline Exon & Aminoacid changes observed & \multicolumn{2}{|c|}{} \\
\hline & Frame 1 & Frame 2 & Frame 3 \\
& $5^{\prime} \rightarrow 3^{\prime}$ & $5^{\prime} \rightarrow 3^{\prime}$ \\
\hline Exon4-intron-exon5 & $\mathrm{W} \rightarrow \mathrm{G}$ & $\mathrm{F} \rightarrow \mathrm{L}$ & $\mathrm{L} \rightarrow \mathrm{W}$ \\
& $\mathrm{Q} \rightarrow \mathrm{R}$ & $\mathrm{G} \rightarrow \mathrm{A}$ & $\mathrm{A} \rightarrow \mathrm{Q}$ \\
& $\mathrm{R} \rightarrow \mathrm{E}$ & $\mathrm{R} \rightarrow \mathrm{E}$ & $\mathrm{E} \rightarrow \mathrm{R}$ \\
& $\mathrm{I} \rightarrow \mathrm{V}$ & $\mathrm{E} \rightarrow \mathrm{K}$ & $\mathrm{N} \rightarrow \mathrm{S}$ \\
\hline Exon 7 & $\mathrm{Q} \rightarrow \mathrm{S}$ & No significant & $\mathrm{V} \rightarrow \mathrm{L}$ \\
& $\mathrm{V} \rightarrow \mathrm{G}$ & similarity found & $\mathrm{V} \rightarrow \mathrm{I}$ \\
& $\mathrm{K} \rightarrow \mathrm{S}$ & & $\mathrm{S} \rightarrow \mathrm{Q}$ \\
& $\mathrm{E} \rightarrow \mathrm{R}$ & $\mathrm{Y} \rightarrow \mathrm{W}$ \\
& $\mathrm{D} \rightarrow \mathrm{G}$ & & $\mathrm{D} \rightarrow \mathrm{K}$ \\
& $\mathrm{P} \rightarrow \mathrm{C}$ & & \\
& $\mathrm{E} \rightarrow \mathrm{G}$ & & \\
& $\mathrm{V} \rightarrow \mathrm{Q}$ & & \\
& $\mathrm{E} \rightarrow \mathrm{M}$ & & \\
& $\mathrm{D} \rightarrow \mathrm{E}$ & & \\
\hline Exon 8 & $\mathrm{K} \rightarrow \mathrm{T}$ & & \\
& $\mathrm{V} \rightarrow \mathrm{I}$ & & \\
& No significant similarity found & No significant & $\mathrm{R} \rightarrow \mathrm{W}$ \\
& & similarity found & $\mathrm{F} \rightarrow \mathrm{G}$ \\
& & & $\mathrm{N} \rightarrow \mathrm{H}$ \\
\hline Exon 9 & $\mathrm{K} \rightarrow \mathrm{N}$ & No change \\
\hline & No significant similarity found & Stop $\rightarrow \mathrm{L}$ & No \\
& & & similarity found \\
\hline
\end{tabular}

